P0-0948 EVOLVING ETHICS SUPPORT TO A CHILDREN'S HOSPITAL

J Brierley, T Radcliffe, M MacLeod. Ethics, Great Ormond St Childrens Hospital NHS Trust, London, UK

\subsection{6/archdischild-2014-307384.1569}

Background and aims Increasing interventions for children with complex problems are leading to moral dilemmas for both professionals and families. We reviewed support to a children's hospital from a bespoke Clinical Ethics Committee (CEC): 20 voluntary members, 1 part-time administrator. (Funded GOSH Children's Charity) Membership: ethics/law, lay/parents, nurses, paediatricians, anaesthetists, surgeons, social care, psychologists, patient advocacy and managers.

Aim Describe activity and case review change from full CEC $<6$ weeks wait to Rapid Responses (RR) -1-5 days.

Methods Retrospective CEC database and minutes review March 2013-14 and same 2009-10.

Results Cases: 2013-14: 14 cases - 1 full CEC and 13 RR, 3 included external hospitals - 1 via videoconference. Parents attended 12. Themes: withdrawal life-sustaining therapy: 3; limitation life-sustaining therapy e.g. ECMO: 5; innovative therapies: 4; capacity/consent: 1, complex dilemma 1. 2009-10: 7 cases - 5 cases CEC, 2 RR. Parents 2. Themes: LLST 3, innovative 2, WLST 2. 3 meetings general ethical aspects of therapy enzyme replacement provision, arteriolysis/thrombolysis for limb salvage and mitochondrial ethical pathway.

Education: $1 \mathrm{PhD}, 2 \mathrm{BSc}$ and 8 SSC medical students - leading to 8 presented abstracts and 2 publications. Lecture series for hospital/other staff. Paediatric Ethics Meeting 'Making Tomorrows People'; 2 CEC education 'away days.' (Judiciary and academic philosophers).

Media: Participation national (BBC) TV and radio ethics programmes and print media.

Conclusions Ethics support to a variety of specialist teams and families is increasing. Support now provided for other hospitals with local reviews or videoconference support. Increasingly prevalent urgent ethics issues have lead to RR being preferred.

\section{PO-0949 BUYING METHYLPHENIDATE ONLINE}

${ }^{1}$ F Finlay, ${ }^{1} \mathrm{H}$ Marcer, ${ }^{2} \mathrm{~J}$ Lane. ${ }^{1}$ Child Health, Sirona, Bath, UK; ${ }^{2}$ Medical School, Bristol Medical School, Bristol, UK

\subsection{6/archdischild-2014-307384.1570}

Background As prescribers of methylphenidate for children with $\mathrm{ADHD}$, we have been interested in following the debate about its use to improve academic performance in healthy students, including medical students. Many are buying psychostimulants online - students should be made aware of potential hazards.

Method We performed a literature review and consulted colleagues in the legal profession, police and pharmacy to clarify implications.

Results

- Buying methylphenidate (controlled drug), without a prescription, is illegal in the UK even if purchased abroad and imported.

- Drugs purchased online may not be what they claim to be.

- Will not receive recommended medical monitoring or follow-up.

- General Medical Council has clear guidance on self- prescribing - 'Wherever possible you must avoid prescribing for yourself or anyone with whom you have a close personal relationship. Controlled medicines present particular dangers, occasionally associated with drug misuse, addiction and misconduct. You must not prescribe a controlled medicine for yourself or someone close to you unless: no other person with the legal right to prescribe is available to assess and prescribe without a delay which would put your, or the patient's, life or health at risk or cause unacceptable pain or distress, and the treatment is immediately necessary to save a life; avoid serious deterioration in health, or alleviate otherwise uncontrollable pain or distress'.

Conclusion Students may not be aware of GMC guidance or may not equate it buying medication online. Students need to be made aware of the risks so they do not inadvertently compromise their health or future careers.

\section{PO-0950 COMPLEMENTARY AND ALTERNATIVE MEDICINE IN CHILDREN: A CROSS SECTIONAL SURVEY OF THE PARENTAL PERCEPTION}

'S Al Sharbatti, 'L Jenny John, 'J Muttappallymyalil, ${ }^{3} \mathrm{~J}$ Sreedharan, ${ }^{4} \mathrm{~J}$ Cheriathu, ${ }^{5} \mathrm{M}$ Moussavi. ${ }^{1}$ Community Medicine, Gulf Medical College Hospital, Ajman, United Arab Emirates; ${ }^{2}$ Pharmacology, Gulf Medical University, Ajman, United Arab Emirates; ${ }^{3}$ CABRI, Gulf Medical College Hospital, Ajman, United Arab Emirates; ${ }^{4}$ Pediatrics, Gulf Medical College Hospital, Ajman, United Arab Emirates; ${ }^{5}$ Pharmacy, Gulf Medical College Hospital, Ajman, United Arab Emirates

\subsection{6/archdischild-2014-307384.1571}

Background and aims The use of Complementary and Alternative Medicine (CAM) has increased over the recent years.

The use of CAM in children is strongly associated with the parent use of CAM and with parent's perception of disease control in their children. The parent's perception regarding the use of CAM among their children was studied.

Methods A cross sectional study was carried out over 12 months, among parents attending Parent-Teachers meeting in selected schools in Ajman, UAE. A self administered validated, pilot tested questionnaire was used as a tool. Descriptive and inferential statistics performed using SPSS-20 and $p$ value $<0.05$ considered significant.

Results A total of 136 parents participated, females [67\%], age below 40 years [54\%], Non-Arabs [65\%], holding Diploma/ Bachelor or higher degree [76\%], and having $\leq 2$ children [61\%]. About 54\% of parents used CAM for their children. Concerning safety of using CAM in children, $79.3 \%$ of parents believed it was safe $189 \%$ of CAM user Vs $28.5 \%$ of CAM nonuser, $\mathrm{p}<0.001) .51 .7 \%$ of the respondents considered use of CAM along with conventional medicine to be safe in children (56.2\% of CAM user Vs $28.5 \%$ of CAM non-user, $\mathrm{p}=0.06$ ). Most frequent source of information regarding CAM for both CAM user and CAM non-user parents was family. The most frequent reason for not using CAM was the belief that modern medicine is more effective.

Conclusions The perception of parents regarding CAM use in children differed between parents who used CAM in their children compared to those who did not.

\section{PO-0951 INFORMATION MANAGEMENT AT JAPAN PAEDIATRIC SOCIETY SUBCOMMITTEES - A SURVEY OF INFORMATION MANAGEMENT AT THE TIME OF ADMISSION}

S Okamoto. Pediatrics, Rakuwakai Otowa Hospital, Kyoto, Japan

10.1136/archdischild-2014-307384.1572 